\title{
Erratum to: Tourism and Transport in a CGE Model and an Illustrative Application
}

\author{
Glyn Wittwer
}

\section{Erratum to:}

Chapter 6 in: G. Wittwer (ed.), Multi-regional Dynamic

General Equilibrium Modeling of the U.S. Economy, Advances in Applied General Equilibrium Modeling, https://doi.org/10.1007/978-3-319-58866-7_6

The original version of the book was inadvertently published with author's incorrect explanatory text in Section 6.2.3. The author provided a new explanatory text "In the case of.......demand overall:" which has been included after Eq. 6.10. Also, the last three paragraphs of the section have been replaced by the new text "The second type of shock......is $1.5 \%$." The erratum chapter and the book have been updated with the changes.

The updated online version of this chapter can be found at https://doi.org/10.1007/978-3-319-58866-7_6 